\title{
ESCOP Herb Referenz
}

\section{Ein praktischer Wegweiser zu pflanzlichen Arzneimitteln}

Die ESCOP teilt mit, dass ein führendes europäisches Spezialistennetzwerk eine App für alle diejenigen erstellt hat, die selbst oder in ihrer Familie pflanzliche Arzneimittel einsetzen. Diese App enthält die wichtigsten verfügbaren Informationen über die Anwendung von mehr als 100 Pflanzen, die in Europa arzneilich verwendet werden. Jedes illustrierte Pflanzenprofil umfasst folgende Punkte:
- Welche Pflanze/Pflanzenteil? (mit den wichtigsten Qualitätskriterien)

- Wie wird sie angewendet?

- Worauf ist bei der Anwendung zu achten?

Man kann dort auch nach Symptomen oder Beschwerdebildern suchen. Dabei erhält man eine Liste möglicher Pflanzen und kann seinen persönlichen Bedürfnis- sen entsprechend eine engere Auswahl treffen.

ESCOP ist ein internationales Netzwerk unabhängiger Experten, die ihr Wissen zur Erstellung detaillierter Dokumentationen zusammenführen (http://escop.com). Die App ist derzeit in Englisch und Deutsch für umgerechnet $€ 1,99$ für Smartphones und Tablets erhältlich und zwar im App Store und bei Google Play.
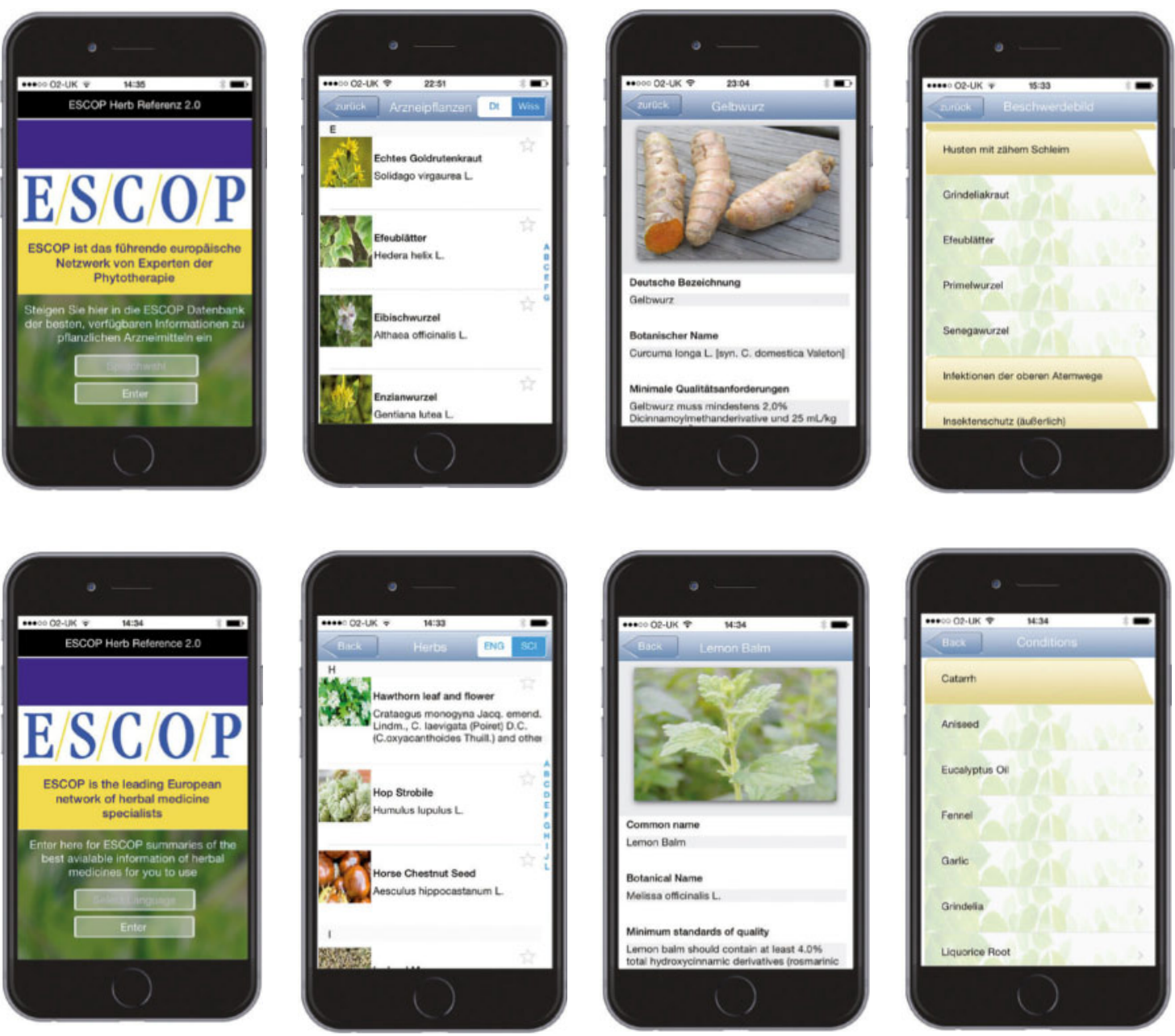